\title{
Projection Neurons in Lamina I of Rat Spinal Cord with the Neurokinin 1 Receptor Are Selectively Innervated by Substance P-Containing Afferents and Respond to Noxious Stimulation
}

\author{
Andrew J. Todd, ${ }^{1}$ Zita Puskár, ${ }^{1,2}$ Rosemary C. Spike, ${ }^{1}$ Catriona Hughes, ${ }^{1}$ Christine Watt, ${ }^{1}$ and Lisa Forrest ${ }^{1}$ \\ ${ }^{1}$ Spinal Cord Group, Institute of Biomedical and Life Sciences, University of Glasgow, Glasgow G12 8QQ, United \\ Kingdom, and 'Department of Anatomy, Histology and Embryology, Faculty of Medicine, Semmelweis University, \\ Budapest, $\mathrm{H}-1094$, Hungary
}

Lamina I of the spinal cord is densely innervated by nociceptive primary afferents, many of which contain substance P. It contains numerous projection neurons: the majority of these respond to noxious stimuli, however some are activated by cooling. In the rat, $\sim 80 \%$ of the projection neurons express the neurokinin 1 (NK1) receptor, on which substance $P$ acts, and most cells with this receptor are activated by noxious stimuli. Lamina I neurons can be classified morphologically into pyramidal, multipolar, and fusiform types. It has been reported in the cat that pyramidal neurons are activated only by cooling and that in monkey relatively few pyramidal cells are NK1 receptor-immunoreactive.

We have used immunocytochemistry to examine the innervation of lamina I projection neurons in the rat by substance $\mathrm{P}$-containing primary afferents and their responses to a noxious stimulus (subcutaneous formalin injection). NK1 receptor- immunoreactive projection cells received a significantly higher density of contacts from substance P-containing afferents than neurons that lacked the receptor. Most contacts on NK1 receptor-immunoreactive cells were associated with synapses. Formalin injection induced c-Fos in $\sim 80 \%$ of projection neurons with the NK1 receptor and in $25-45 \%$ of those without it. More than $80 \%$ of pyramidal neurons expressed the receptor, and for both substance $P$ innervation and $c$-Fos expression there were no significant differences among different morphological types of NK1 receptor-immunoreactive neuron.

We conclude that presence or absence of the NK1 receptor is a better indicator of function than morphology for lamina I projection neurons in the rat.

Key words: pain; c-Fos; confocal microscopy; electron microscopy; synapse; calcitonin gene-related peptide
The importance of lamina I in nociception has long been recognized. Most neurons in this lamina respond to noxious stimulation (Christensen and Perl, 1970; Light et al., 1979; Ferrington et al., 1987; Han et al., 1998; Bester et al., 2000), and many have ascending axons that project to brain regions that have a role in pain mechanisms, including the medullary reticular formation, parabrachial area, periaqueductal gray matter, and thalamus (Trevino and Carstens, 1975; Giesler et al., 1979; Menétrey et al., 1982; Lima et al., 1991; Craig, 1995; Villanueva and Bernard, 1999). Many nociceptive primary afferents contain substance $P$ (Lawson et al., 1997), and the central terminals of these afferents form a dense plexus in the superficial laminas (Hökfelt et al., 1975). Substance $P$ acts on the neurokinin 1 (NK1) receptor, which is concentrated in lamina I (Bleazard et al., 1994; Nakaya et al., 1994; Vigna et al., 1994; Brown et al., 1995; Littlewood et al., 1995; Todd et al., 1998) and is expressed by $\sim 80 \%$ of projection neurons in this lamina (Marshall et al., 1996; Todd et al., 2000). The majority of lamina I neurons with the NK1 receptor are thought to be activated by nociceptors, because most show internalization of the receptor (Mantyh et al., 1995) or express c-Fos (Doyle and Hunt, 1999) after noxious stimulation. Intra-

\footnotetext{
Received Dec. 6, 2001; revised Jan. 23, 2002; accepted Jan. 24, 2002.

We thank M. M. McGill and R. Kerr for expert technical assistance and the Wellcome Trust for financial support.

Correspondence should be addressed to Dr. A. J. Todd, Spinal Cord Group, West Medical Building, University of Glasgow, University Avenue, Glasgow G12 8QQ, UK. E-mail: a.todd@bio.gla.ac.uk.

Copyright (ㄷ) 2002 Society for Neuroscience $\quad 0270-6474 / 02 / 224103-11 \$ 15.00 / 0$
}

thecal administration of substance $\mathrm{P}$ conjugated to the cytotoxin saporin selectively destroys NK1 receptor-immunoreactive neurons in the superficial dorsal horn and dramatically reduces the development of hyperalgesia after capsaicin treatment, indicating that these cells play an important role in the development of hyperalgesia (Mantyh et al., 1997). Less is known about the functions of lamina I projection neurons that lack the NK1 receptor.

Lamina I neurons have also been classified according to the morphology of their cell bodies and dendritic trees, which are best seen in horizontal sections. Gobel (1978) identified pyramidal and multipolar neurons in lamina I of cat spinal trigeminal nucleus, and more recent studies have divided projection neurons in this lamina into three major classes: pyramidal, fusiform, and multipolar (or flattened) cells (Lima et al., 1991; Zhang et al., 1996; Zhang and Craig, 1997). In an intracellular recording study in the cat, Han et al. (1998) found that cells of each morphological type had characteristic receptive field properties: pyramidal neurons responded exclusively to innocuous cooling, whereas fusiform and multipolar cells were activated by noxious stimuli. Consistent with this finding, Yu et al. (1999) reported that most pyramidal cells in lamina I of the monkey did not possess the NK1 receptor, although Cheunsuang and Morris (2000) found many NK1 receptor-immunoreactive pyramidal neurons in lamina I of the rat spinal cord.

In this study we have investigated lamina I projection neurons in the rat, to determine whether (1) the density of innervation by substance P-containing (nociceptive) primary afferents, and (2) 
responsiveness to an acute noxious stimulus (as judged by c-Fos expression; Hunt et al., 1987) were more closely related to morphology or to expression of the NK1 receptor.

\section{MATERIALS AND METHODS}

Animals and general features of tissue preparation. Eleven adult male Wistar rats (Harlan, Loughborough, UK; 270-340 gm) were deeply anesthetized either with halothane or with a mixture of ketamine and xylazine ( 7.33 and $0.73 \mathrm{mg} / 100 \mathrm{gm}$, i.p., respectively, supplemented as necessary) and placed in a stereotaxic frame. Each rat received an injection of either 200-250 nl 1\% cholera toxin B subunit (CTb; Sigma, Poole, UK) or 50-100 nl 4\% Fluorogold (Fluorochrome Inc., Englewood, $\mathrm{CO}$ ) through a glass micropipette into the brainstem on the left side. In all cases the injections were targeted on the caudal ventrolateral medulla (CVLM) and specifically the region between the spinal trigeminal nucleus and the lateral reticular nucleus, because injections in this region label many lamina I neurons in the rat (Lima et al., 1991; Todd et al., 2000). Fluorogold was used as a tracer in experiments to investigate contacts from substance P-containing primary afferents onto NK1 receptor-immunoreactive lamina I projection neurons with confocal microscopy (three rats) or combined confocal and electron microscopy (three rats). CTb was used for studies of contacts formed by substance P-containing axons onto lamina I projection neurons that lacked the NK1 receptor (two rats) and also for experiments in which a terminal acute noxious stimulus was applied to induce c-Fos expression (three rats). In all cases the rats survived 3 or $4 \mathrm{~d}$ after the tracer injection before either perfusion or noxious stimulation under terminal general anesthesia (see below).

Contacts between SP axons and lamina I projection neurons. Eight of the rats (six with Fluorogold and two with $\mathrm{CTb}$ ) were reanesthetized with pentobarbitone and perfused with a fixative containing $4 \%$ freshly depolymerized formaldehyde (confocal microscopy alone) or $4 \%$ formaldehyde $-0.2 \%$ glutaraldehyde $-0.2 \%$ picric acid (combined confocal and electron microscopy). The brain and lumbar spinal cord segments were removed and stored for 4-24 hr in fixative. The region of the brainstem that included the injection site was cryoprotected with $30 \%$ sucrose overnight and cut into $100-\mu \mathrm{m}$-thick coronal sections with a freezing microtome. Every fifth section was kept and either mounted directly onto slides (Fluorogold injections) or reacted with goat antiserum against $\mathrm{CTb}$ (List Biological Laboratories, Campbell, CA; 1:50,000) using an immunoperoxidase method (Todd et al., 2000). The spread of tracer from the injection site in each case was plotted onto drawings of the brainstem (Paxinos and Watson, 1997).

Lumbar spinal cord segments were notched (so that the right and left sides could be distinguished) and were then cut into $70-\mu \mathrm{m}$-thick horizontal sections with a Vibratome. The sections were treated with $50 \%$ ethanol for $30 \mathrm{~min}$ to enhance antibody penetration (Llewellyn-Smith and Minson, 1992), and those from animals fixed with glutaraldehyde were incubated for $30 \mathrm{~min}$ in $1 \%$ sodium borohydride. After rinsing, sections were incubated for $3 \mathrm{~d}$ in one of the following cocktails of primary antibodies: (1) rabbit antiserum against NK1 receptor (Sigma; diluted 1:10,000), rat monoclonal antibody against substance P (SeraLab, Crawley Down, UK; 1:200), and sheep antiserum against calcitonin gene-related peptide (CGRP) (Affiniti, Exeter, UK; 1:5000) or (2) rabbit anti-NK1 receptor and rat anti-substance $\mathrm{P}$ (as above) and goat antiserum against $\mathrm{CTb}$ (List; 1:5000). The first antibody combination was used on sections from Fluorogold-injected rats for the study of contacts formed by substance P-CGRP-containing axons onto NK1 receptorimmunoreactive projection neurons with either confocal or combined confocal and electron microscopy. The second combination was used on sections from CTb-injected animals to investigate contacts from substance P-containing axons onto projection neurons that lacked the NK1 receptor.

Sections that were to be examined only with confocal microscopy were incubated for $1 \mathrm{~d}$ in secondary antibodies (anti-rabbit, anti-rat, and anti-goat $\mathrm{IgG}$ ) each conjugated to a different fluorochrome (fluorescein, rhodamine, or cyanine 5.18) (all raised in donkey, obtained from Jackson ImmunoResearch, West Grove, PA, and diluted 1:100), mounted in anti-fade medium (Vectashield; Vector Laboratories, Peterborough, UK), and stored at $-20^{\circ} \mathrm{C}$ until needed. For sections that were to be processed by the confocal-electron microscopic technique the same combination of secondary antibodies was used, but this also included biotinylated donkey anti-rat IgG (Jackson; 1:500). The sections were then rinsed, incubated in avidin conjugated to horseradish peroxidase (Extra- vidin peroxidase; Sigma, 1:1000), and mounted in Vectashield. After the completion of confocal microscopy (see below), the sections were removed from slides, rinsed in buffer, reacted for $5 \mathrm{~min}$ with 3,3'diaminobenzidine in the presence of hydrogen peroxide to reveal substance $\mathrm{P}$ immunoreactivity, osmicated $\left(1 \% \mathrm{OsO}_{4}\right.$ for $\left.20 \mathrm{~min}\right)$, block stained in uranyl acetate, dehydrated in acetone, and flat-embedded in Durcupan that was cured at $60^{\circ} \mathrm{C}$ for $48 \mathrm{hr}$. Serial ultrathin sections were cut through regions of interest with a diamond knife, mounted onto Formvar-coated single-slot grids, contrasted with lead citrate, and viewed with a Philips CM100 transmission electron microscope.

For sections used for confocal microscopy alone, antibodies were diluted in PBS that contained $0.3 \%$ Triton X-100. Triton was omitted for sections that were to be used for combined confocal and electron microscopy.

Analysis of contacts. Thirty NK1 receptor-immunoreactive projection neurons were selected from rats injected with Fluorogold and perfused with formaldehyde (10 neurons from each of the three rats). To avoid bias, the selection was made before peptide immunoreactivity was examined. Because we intended to compare projection neurons belonging to different morphological classes, only cells that could be unequivocally assigned to pyramidal, multipolar, or fusiform classes were selected. For each neuron digital images of the Fluorogold in the cell body were captured with a Zeiss Axiocam using an ultraviolet filter set. The cell body and as much of the dendritic tree as could be followed were then scanned with a Bio-Rad MRC1024 confocal microscope equipped with a krypton-argon laser. Sequential scanning with each line of the laser was performed using a $40 \times$ oil-immersion objective to produce $z$-series with a $z$-separation of $0.5 \mu \mathrm{m}$. The resulting images were analyzed with Neurolucida for Confocal (MicroBrightField, Inc., Colchester, VT). The positions of all contacts which the cells received from axonal varicosities that were both substance P- and CGRP-immunoreactive were plotted onto drawings of the neurons. The lengths of dendrites were measured, and their surface areas were estimated based on the assumption that they were cylindrical. The surface areas of cell bodies were also measured, and the number of contacts per $1000 \mu \mathrm{m}^{2}$ of combined dendritic and somatic membrane was determined for each cell.

Ten projection neurons that lacked NK1 receptors were analyzed (five each from two rats injected with $\mathrm{CTb}$ ) in the same way, except that in these cases contacts from all substance P-immunoreactive axonal varicosities were counted (because CGRP was not detected in these sections).

Combined confocal and electron microscopy was performed on six cells (between one and three each from three rats injected with Fluorogold and perfused with formaldehyde-glutaraldehyde-picric acid). Cells with numerous contacts from substance P-CGRPimmunoreactive axonal varicosities near one surface of the Vibratome section were selected, because penetration of the immunoperoxidase staining is often incomplete with the combined method. The cells were scanned with the confocal microscope and then processed as described above. Ultrathin sections were cut through regions containing these contacts, and between 20 and 25 contacts that had been identified with confocal microscopy were examined with the electron microscope for the presence of synapses.

c-Fos expression by projection neurons. Three rats that had been injected with $\mathrm{CTb}$ were reanesthetized with ketamine and xylazine and received injections of $2 \%$ formaldehyde into the plantar pad and digits of the right hindpaw (100 $\mu \mathrm{l}$ in total). They were maintained under anesthetic for $2 \mathrm{hr}$, injected with intraperitoneal pentobarbitone, and fixed by perfusion with $4 \%$ formaldehyde. Brain and lumbar spinal cord segments were post-fixed for $4 \mathrm{hr}$, and transverse sections through the caudal medulla were used to demonstrate the injection site (as described above). Horizontal Vibratome sections of spinal cord were reacted for tripleimmunofluorescent labeling with goat anti-CTb (List; 1:5000), guinea pig antiserum against NK1 receptor (Polgár et al., 1999; diluted 1:1000), and rabbit anti-c-Fos (Hunt et al., 1987; diluted 1:5000) and corresponding secondary antibodies labeled with rhodamine, fluorescein, or cyanine 5.18 (Jackson; 1:100). Two or three of the sections from the L4 segment that included lamina I were scanned at low magnification to reveal c-Fos and $\mathrm{CTb}$, and projected images of these scans were used to plot the outlines of the medial region of lamina I in which c-Fos-immunoreactive neurons were present. The presence of c-Fos in individual projection neurons was not examined at this stage. High-magnification sequential $z$-series (40× objective lens; $5 \mu \mathrm{m} z$-separation) of the entire medial part of lamina I in each section were then scanned to detect CTb, NK1 receptor, and c-Fos immunoreactivity. The files containing $\mathrm{CTb}$ and 
NK1 receptor immunoreactivity were analyzed with Neurolucida for Confocal and from each animal 30 NK1 receptor-immunoreactive projection neurons belonging to each of the three main morphological classes (pyramidal, fusiform, and multipolar) were selected, together with 20 projection neurons that lacked the receptor. For the NK1 receptor-immunoreactive neurons, only those that could be unequivocally assigned to one of these morphological classes were selected. The cell bodies and proximal dendrites of these cells were drawn, and their locations were plotted onto the outline of the dorsal horn. Files containing $\mathrm{CTb}, \mathrm{NK} 1$ receptor, and c-Fos immunoreactivity were then used to determine whether the nuclei of the selected cells contained c-Fos.

NK1 receptor-immunostaining of pyramidal cells. Because $\mathrm{Yu}$ et al. (1999) reported that only $25 \%$ of pyramidal spinothalamic neurons in the monkey were NK1 receptor-immunoreactive, we estimated the proportion of retrogradely labeled pyramidal neurons that expressed the NK1 receptor in sections from the three rats that had been used for the c-Fos experiments. The files containing $\mathrm{CTb}$ that had been scanned and analyzed for c-Fos were reexamined, and all of the immunoreactive neurons that could be unequivocally identified as pyramidal cells were drawn with Neurolucida and counted. The corresponding files of NK1 receptor-immunostaining were then used to determine whether each cell possessed the receptor.

\section{RESULTS}

\section{Injection sites and general features of retrograde labeling and immunostaining in lamina I}

In all cases the injection sites included the region between the lateral part of the lateral reticular nucleus and the spinal trigeminal nucleus, however there was usually spread into both of these structures and also into surrounding parts of the reticular formation (Fig. 1). Fluorogold injections contained a necrotic core and a surrounding halo, whereas $\mathrm{CTb}$ injections produced a more restricted spread of tracer (Figs. 1, 2). In all cases numerous retrogradely labeled neurons were seen on the contralateral side in lamina I of the lumbar spinal cord (Fig. 3).

Penetration of immunofluorescence staining with each antibody appeared to be complete in spinal cord sections that were processed only for confocal microscopy. CTb-labeled lamina I projection neurons generally showed extensive dendritic filling, and dendrites could usually be followed for at least $100 \mu \mathrm{m}$ or until they left the section (Fig. 3). Many of the labeled cells could be allocated to one of the three main morphological classes (pyramidal, multipolar, or fusiform), however many cells either showed atypical features or were transitional in shape. Fluorogold was not detected by the confocal microscope, however the morphology of Fluorogold-labeled neurons that were NK1 receptorimmunoreactive could be examined in confocal images of NK1 receptor immunostaining (Fig. 4).

\section{Quantitative analysis of substance P-CGRP contacts on projection neurons}

All of the 30 NK1 receptor-immunoreactive Fluorogold-labeled cells that were analyzed received contacts on their cell bodies and dendrites from substance P-immunoreactive axonal varicosities, and the great majority of these varicosities also contained CGRP immunoreactivity. Examples of contacts on two of the cells that were analyzed are illustrated in Figures 4 and 5. The density of contacts varied on different parts of each cell: in all cases there were regions that received few contacts, however all of the cells also had patches of membrane on which numerous contacts from substance P-CGRP-immunoreactive varicosities were present, often outlining parts of the cell body and dendrites (Figs. $4 c, 5$ ). Contacts occurred on both proximal and distal dendrites, and we did not find any evidence of preferential innervation of particular parts of the dendritic tree. The mean density of contacts that these cells received from substance P-CGRP-containing varicos-
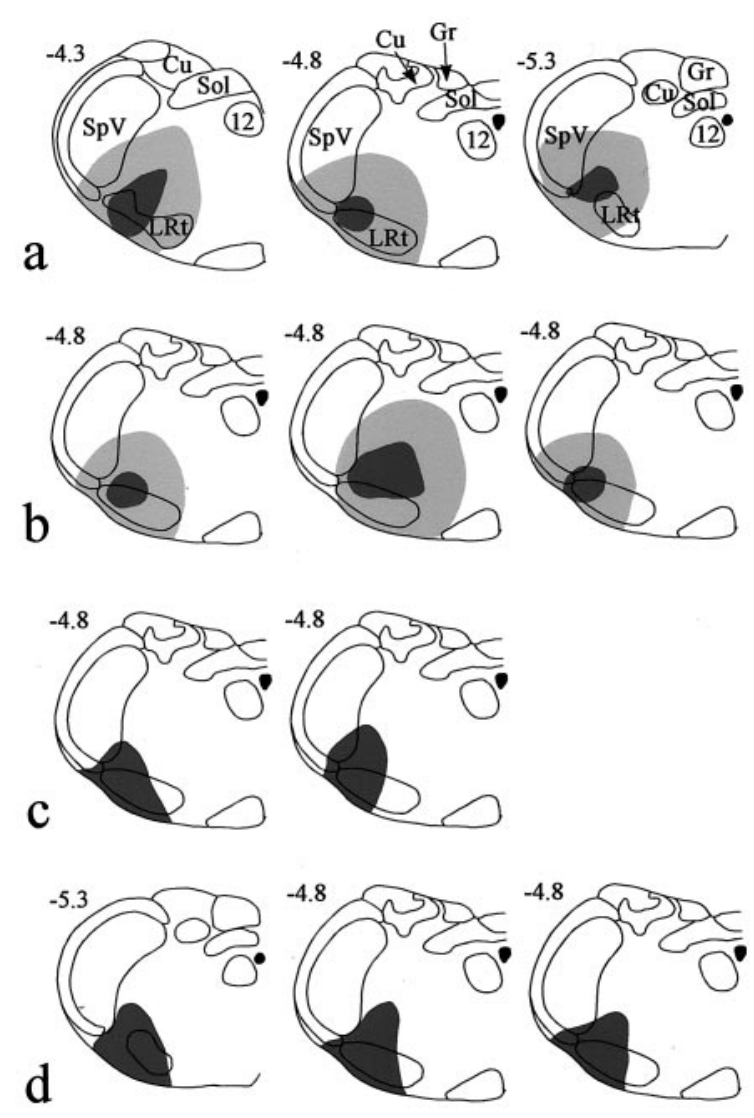

Figure 1. Diagrams to show the spread of tracer in each of the 11 experiments. The drawings in each horizontal row are from rats used for a single part of the study. $a$, Fluorogold injections for confocal microscopic analysis of substance P-CGRP contacts on NK1 receptorimmunoreactive projection neurons; $b$, Fluorogold injections for combined confocal-electron microscopy of contacts; $c$, CTb injections for analysis of substance P contacts on projection neurons that lacked NK1 receptors; $d$, CTb injections for c-Fos experiments. For Fluorogold injections, the dark shaded area shows the necrotic core of the injection, and the paler area the halo of tracer, whereas for CTb injections, the shaded area shows the extent of $\mathrm{CTb}$ immunostaining in the injection site. In each case, the drawing shows the level of the medulla at which the maximum spread of tracer was present. Numbers at the top left of each drawing give the approximate position of the section posterior to the ear bar. Drawings are based on those by Paxinos and Watson (1997). 12, Hypoglossal nucleus; $C u$, cuneate nucleus; $G r$, gracile nucleus; $L R t$, lateral reticular nucleus; Sol, tractus and nucleus solitarius; $S p V$, spinal trigeminal nucleus.

ities was 23.1/1000 $\mu \mathrm{m}^{2}$ ( \pm 1.1 SEM; range, 13.5-38.4). Most of the cells also received a few contacts from substance P-immunoreactive varicosities that lacked CGRP. The proportion of substance P-immunoreactive varicosities in contact with the cells that were also CGRP-immunoreactive varied from 89.7 to $100 \%$ (mean, $97.2 \pm 0.5 \%$ ). The 30 neurons analyzed in this part of the study included 10 pyramidal cells, 11 multipolar cells, and 9 fusiform cells, and the mean values for density of contacts from substance P-CGRP-immunoreactive varicosities per $1000 \mu \mathrm{m}^{2}$ for each type were $21.5( \pm 2.2), 24.8( \pm 1.4)$, and $22.6( \pm 2.3)$, respectively. These values were not significantly different (oneway ANOVA). To allow comparison of these cells with NK1 receptor-immunoreactive projection neurons that have cell bodies in laminas III and IV (Naim et al., 1997), we also determined the density of contacts from substance P-CGRP-immunoreactive 

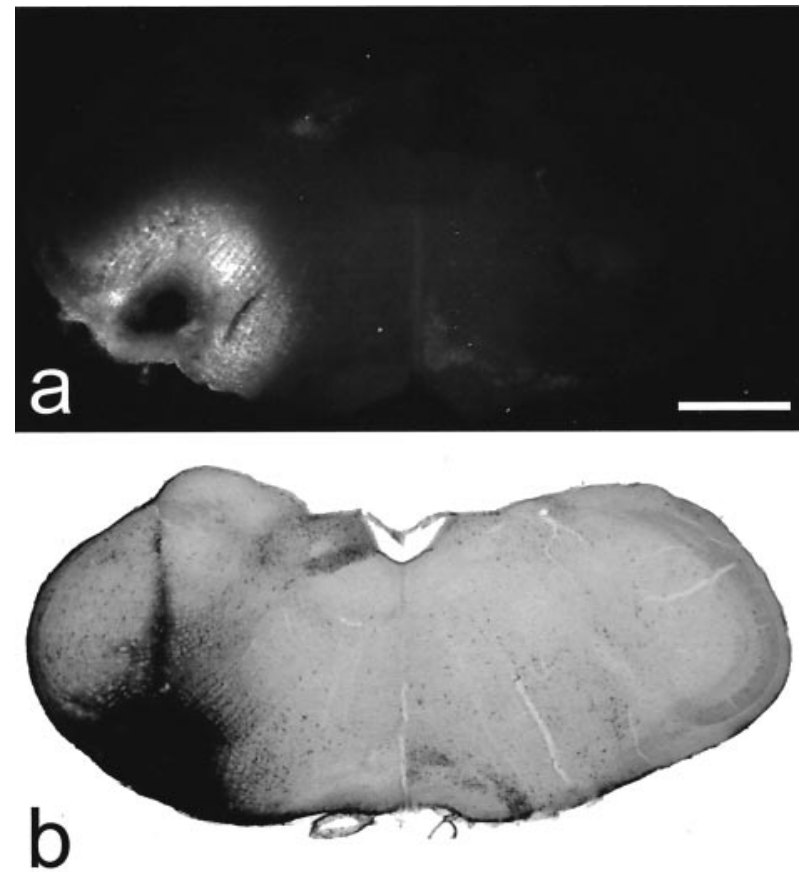

Figure 2. Examples of sections through injection sites with Fluorogold or CTb. $a$ shows Fluorogold seen with epifluorescence illumination and an ultraviolet filter set, whereas $b$ is a section reacted to reveal CTb with an immunoperoxidase method. Scale bar, $1 \mathrm{~mm}$.

varicosities per $100 \mu \mathrm{m}$ length of dendrite. The mean density was 16.2 contacts $/ 100 \mu \mathrm{m}( \pm 0.7)$.

The $10 \mathrm{CTb}$-labeled cells that were not NK1 receptorimmunoreactive also received contacts from substance Pimmunoreactive varicosities, however, these tended to be less numerous than those on the NK1 receptor-immunoreactive neurons. Regions with densely packed contacts from substance $\mathrm{P}$-immunoreactive varicosities were never seen on these cells. The mean density of contacts was $12.9 / 1000 \mu \mathrm{m}^{2}( \pm 1.0$; range, 9.117.9), and this was significantly different from the mean density of contacts from substance P-CGRP-immunoreactive varicosities on the $30 \mathrm{NK} 1$ receptor-immunoreactive neurons ( $t$ test; $p<$ 0.001).

\section{Electron microscopy of contacts}

Six Fluorogold-labeled NK1 receptor-immunoreactive projection neurons were examined with combined confocal and electron microscopy: this sample included three multipolar, two pyramidal, and one fusiform cell. Between 20 and 25 contacts from substance P-CGRP-immunoreactive varicosities onto each of the neurons were found with the electron microscope. Most of these contacts involved dendrites of the neurons, but for five of the cells one or more axosomatic contacts were also examined. Asymmetrical synapses were seen at between 74 and $95 \%$ of these contacts (mean $84 \%$ ). Six contacts onto one of the multipolar cells are illustrated in Figures 6 and 7.

\section{c-Fos expression by lamina I projection neurons}

Many c-Fos-immunoreactive nuclei were seen in the medial part of the superficial dorsal horn on the ipsilateral side after formalin injection into the right hindpaw. These were present in lamina I (which could be identified in horizontal sections by the high density of NK1 receptor immunostaining) and also in the region that lay immediately below this (i.e., lamina II). In each of the three animals, $30 \mathrm{NK} 1$ receptor-immunoreactive projection neurons belonging to each of the three morphological types were analyzed, and the majority of these (between 20 and 28 of 30) had nuclei that were c-Fos-immunoreactive (Table 1). No differences were found between the results for the different morphological classes of NK1 receptor-immunoreactive projection neuron (oneway ANOVA). Nuclear c-Fos immunoreactivity was much less common in the population of projection neurons that lacked the NK1 receptor (between 5 and 9 of 20) (Table 1). Comparison of cells that lacked the $\mathrm{NK} 1$ receptor with the NK1 receptorimmunoreactive neurons analyzed from each experiment showed that these two groups were significantly different ( $t$ test; $p<0.05$ ). Examples of c-Fos expression by different types of lamina I projection neuron are shown in Figure 8.

\section{NK1 receptor-immunoreactive pyramidal cells}

The total numbers of CTb-labeled cells that were identified as pyramidal neurons in the regions of the L4 segments scanned from the three rats varied from 40 to 59, and between 80 and $86 \%$ of these cells were NK1 receptor-immunoreactive (33 of 40, 51 of 59 , and 37 of 46). Figure $8 a$ includes two pyramidal neurons, one that was NK1 receptor-immunoreactive $(\mathrm{P})$, and one that lacks the receptor $(\mathrm{N})$.

\section{DISCUSSION}

The main findings of this study were that lamina I projection neurons with the NK1 receptor received more numerous contacts from substance P-containing primary afferents (most of which were associated with synapses) and were more likely to express c-Fos after injection of formalin into the hindpaw than those that lacked the receptor. However, there were no significant differences in terms of either innervation density or c-Fos expression among different morphological types of NK1 receptorimmunoreactive projection neuron.

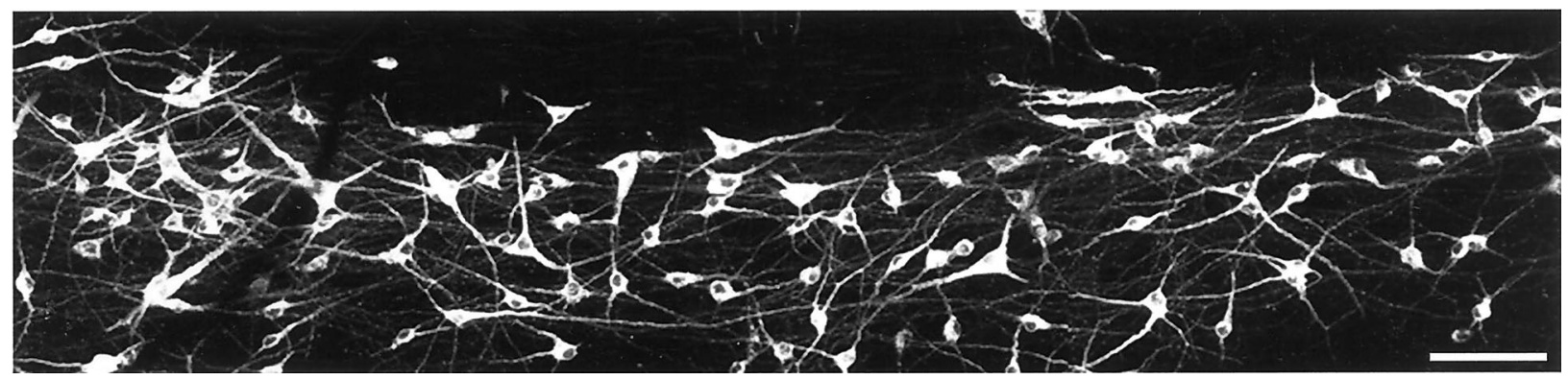

Figure 3. Examples of lamina I neurons retrogradely labeled with $\mathrm{CTb}$ and detected with immunofluorescence in a horizontal section. Note the large number of labeled cells and the extensive dendritic filling. Scale bar, $100 \mu \mathrm{m}$. 

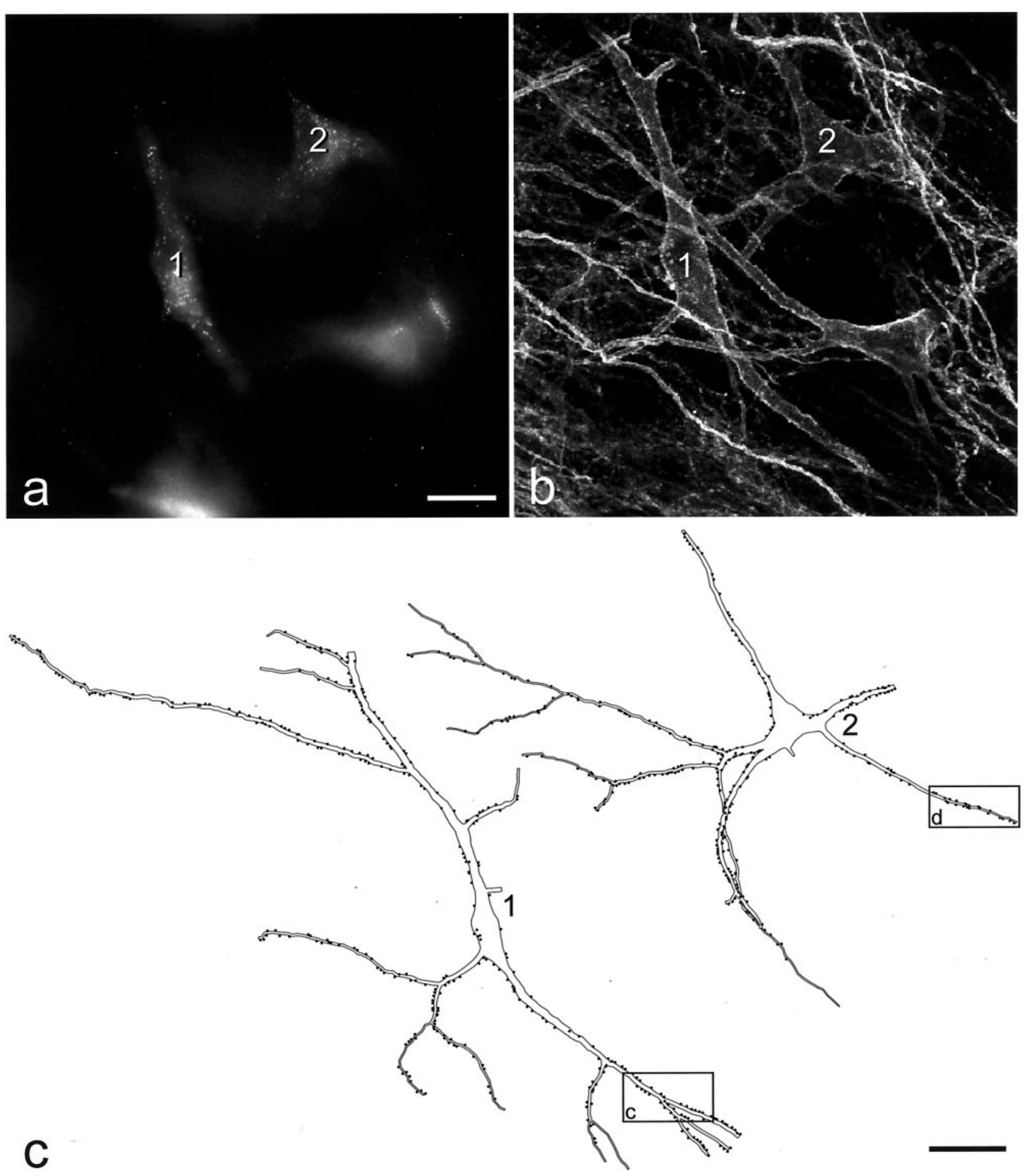

Figure 4. Two of the NK1 receptor-immunoreactive lamina I projection neurons included in the quantitative analysis of contacts from substance P primary afferents. $a$, Photograph of Fluorogold labeling in the two cells $(1,2)$ taken with an ultraviolet filter set. $b$, Confocal image of the corresponding field scanned to reveal NK1 receptor that is present on both cells and outlines their cell bodies and proximal dendrites. Cell 1 is a fusiform cell, and cell 2 is a pyramidal cell. Built from 11 optical sections at $1 \mu \mathrm{m} z$-spacing. $c$, Drawings of the two cells showing the contacts that they received from axonal varicosities that were immunoreactive with both substance P and CGRP antibodies. Each dot represents a single contact. Boxes show parts of the dendritic tree of each cell that are illustrated in Figure 5. Scale bars: $a, b, 25 \mu \mathrm{m} ; c, 50 \mu \mathrm{m}$.

\section{Injection site and retrograde tracers}

The CVLM was chosen as an injection site, because in previous studies we found that more lamina I neurons were retrogradely labeled from this region than from other projection targets (Mar- shall et al., 1996; Todd et al., 2000). We have recently injected Fluorogold into the parabrachial area and CTb into the CVLM in rats and found that most retrogradely labeled lamina I neurons contained both tracers (A. J. Todd and Z. Puskár, unpublished 


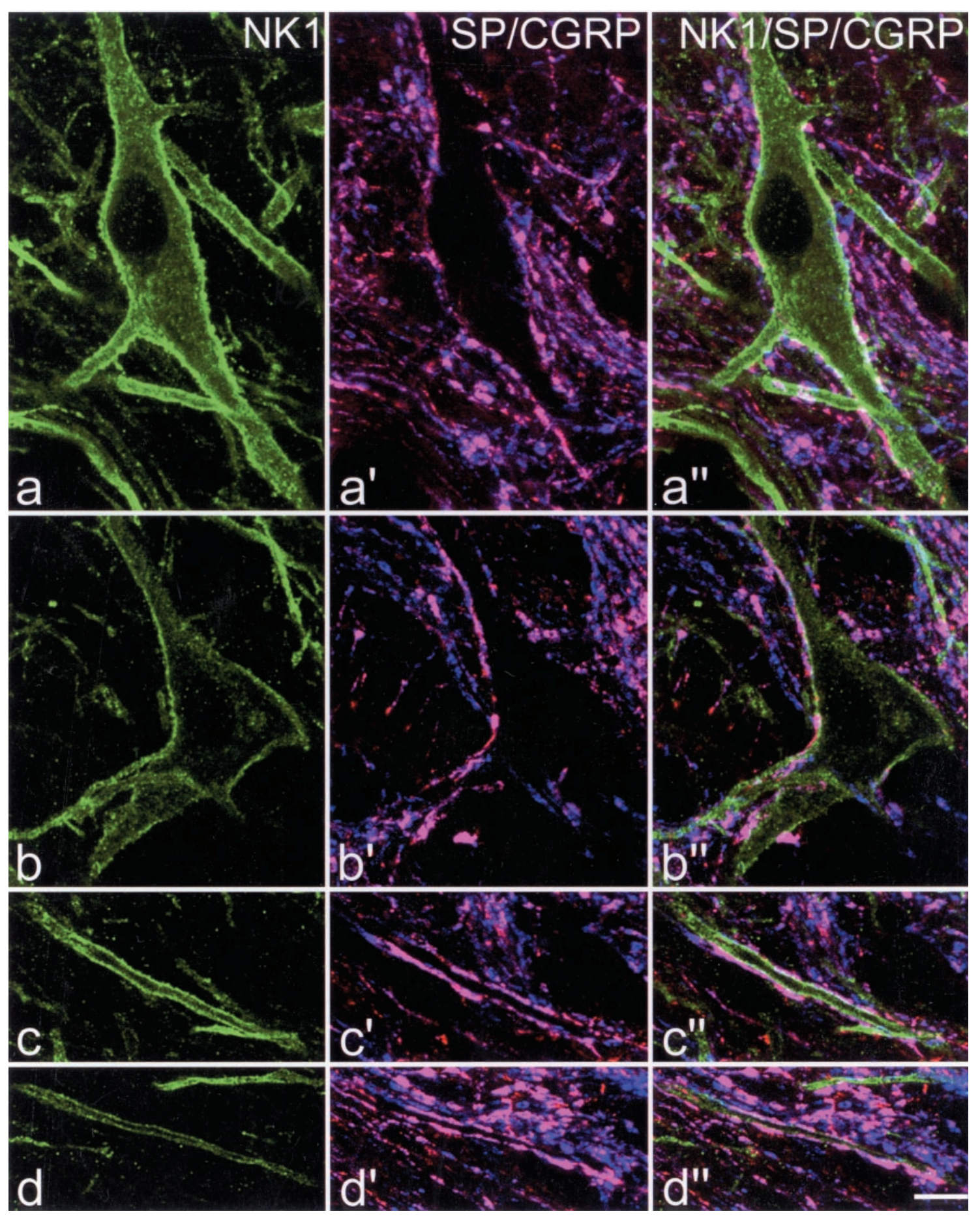

Figure 5. Confocal images showing contacts from substance $\mathrm{P}$ primary afferents onto the cell bodies and dendrites of the two NK1 receptorimmunoreactive lamina I projection neurons illustrated in Figure 4. In each row, the left image shows NK1 receptor (green), the middle image shows substance P (red) and CGRP (blue), whereas in the right image all three colors have been merged. Profiles that contain both peptides appear purple. $a$ and $b$ show the cell bodies of cells 1 and 2, whereas $c$ and $d$ include parts of a dendrite from each cell (corresponding to boxes in Fig. 4c). There are several contacts formed by axons that contain both substance P and CGRP on each cell body, and the dendrites receive so many contacts in these regions that they are outlined by immunoreactive axons. The images in $a-d$ are built from projections of $6,4,5$, and 4 optical sections, respectively, at $0.5 \mu \mathrm{m}$ $z$-separation. Scale bar, $10 \mu \mathrm{m}$.

observations). This suggests that many of the cells examined in the present study projected to the parabrachial area. We have found that numbers of retrogradely labeled lamina I neurons were far higher after injections into CVLM or parabrachial area than after injections into dorsal reticular nucleus, periaqueductal gray matter, or thalamus (Marshall et al., 1996; Todd et al., 2000), and it is therefore likely that the great majority of lamina I projection neurons were labeled in this study.

Because Fluorogold was not detected by the confocal microscope, we were able to perform triple-labeling immunocytochem- 

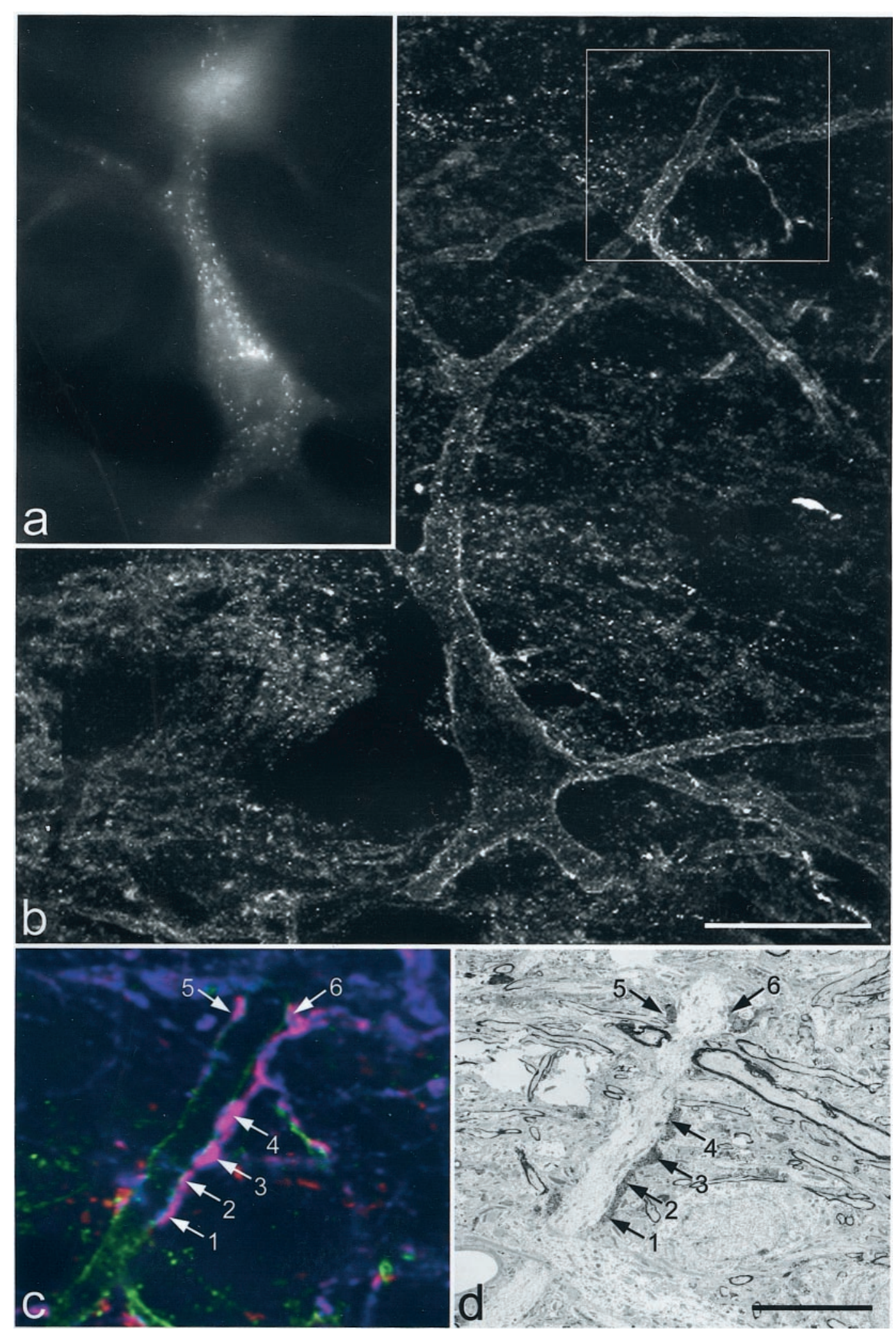

Figure 6. One of the multipolar cells examined with combined confocal and electron microscopy. $a$, Epifluorescence image taken with ultraviolet filter set to show Fluorogold in the cell body. $b$, Confocal image showing the NK1 receptor, which can be seen on the cell body and proximal dendrites (projected from 4 optical sections at $1 \mu \mathrm{m} z$-separation). The box shows the region illustrated in $c$ and $d . c$, Confocal image showing a single optical section through the dendrite scanned to reveal NK1 receptor ( green), substance P (red), and CGRP (blue). The dendrite is in contact with six axonal varicosities that contain both peptides and therefore appear purple (numbered arrows). $d$, Low-magnification electron micrograph through the region corresponding to the confocal image in $c$. The six axonal varicosities are labeled with diaminobenzidine, which has been used to reveal substance P immunoreactivity, and can just be seen at this magnification. Scale bars: $a, b, 25 \mu \mathrm{m} ; c, d, 10 \mu \mathrm{m}$. 


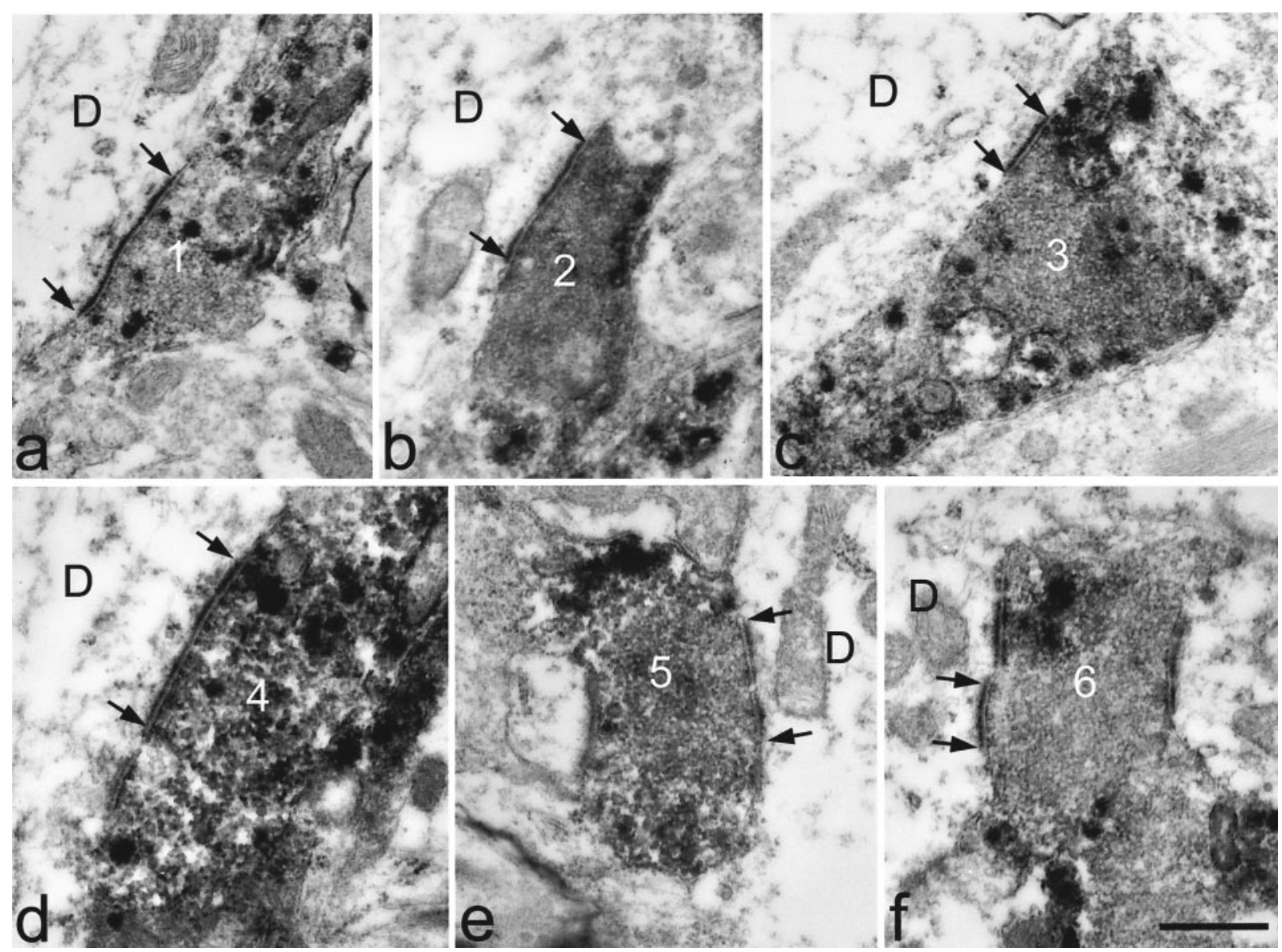

Figure 7. High-magnification electron micrographs of the six substance P-CGRP-immunoreactive axonal varicosities illustrated in Figure $6 d$, taken either from the same ultrathin section or from one nearby in the series. In each case the labeled axon forms an asymmetrical synapse with the dendrite $(D)$. The synaptic specialization is visible between the arrows. Numbers on the axons correspond to those in Figure $6, c$ and $d$. Scale bar, $0.5 \mu \mathrm{m}$.

Table 1. Results of c-Fos experiments

\begin{tabular}{|c|c|c|c|c|c|}
\hline \multirow[b]{2}{*}{ Type of cell } & \multirow{2}{*}{$\begin{array}{l}\text { Sample size/ } \\
\text { experiment }\end{array}$} & \multicolumn{3}{|c|}{ Number c-Fos-immunoreactive } & \multirow[b]{2}{*}{ Mean $\%$} \\
\hline & & Experiment 1 & Experiment 2 & Experiment 3 & \\
\hline NK1 + pyramidal & 30 & 25 & 23 & 26 & 82.2 \\
\hline NK1 + multipolar & 30 & 28 & 20 & 23 & 78.9 \\
\hline $\mathrm{NK} 1$ + fusiform & 30 & 22 & 26 & 21 & 76.7 \\
\hline NK1- & 20 & 5 & 7 & 9 & 35 \\
\hline
\end{tabular}

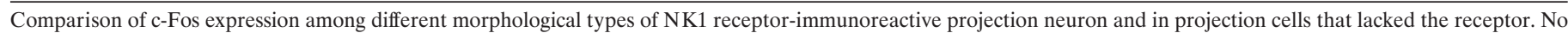

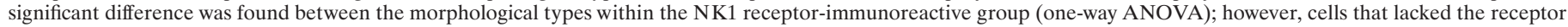
showed significantly lower expression of c-Fos than those with the receptor $(t$ test; $p<0.05)$.

istry when this tracer was used. In addition to identifying projection neurons with the NK1 receptor, we could therefore also detect substance $\mathrm{P}$ and CGRP. Immunostaining for these peptides can be used to identify substance P-containing primary afferents, because all of these contain CGRP in the rat, and CGRP is restricted to primary afferents in the dorsal horn (Ju et al., 1987; Todd and Spike, 1993). The NK1 receptor antibody outlined somata and dendrites of Fluorogold-labeled projection neurons that expressed the receptor, which allowed us to examine contacts from substance $\mathrm{P}$ afferents onto these cells (Figs. 4-6). To investigate contacts onto projection neurons that lacked the $\mathrm{NK} 1$ receptor, we used $\mathrm{CTb}$ as a retrograde tracer, because this gave excellent dendritic labeling that could be revealed with confocal microscopy (Figs. 3, 8). Because CTb was detected with immunocytochemistry, only two other antibodies could be used, and because the NK1 receptor antibody was needed to identify cells that lacked the receptor, we could detect substance P, but not CGRP (see below).

\section{Morphology, substance P innervation, and c-Fos expression}

Although many of the retrogradely labeled cells could be classified as pyramidal, fusiform, or multipolar, it was often not possible to allocate a neuron unequivocally to one class, because many cells showed atypical features or were transitional in shape. To avoid problems of interpretation when comparing cells in differ- 


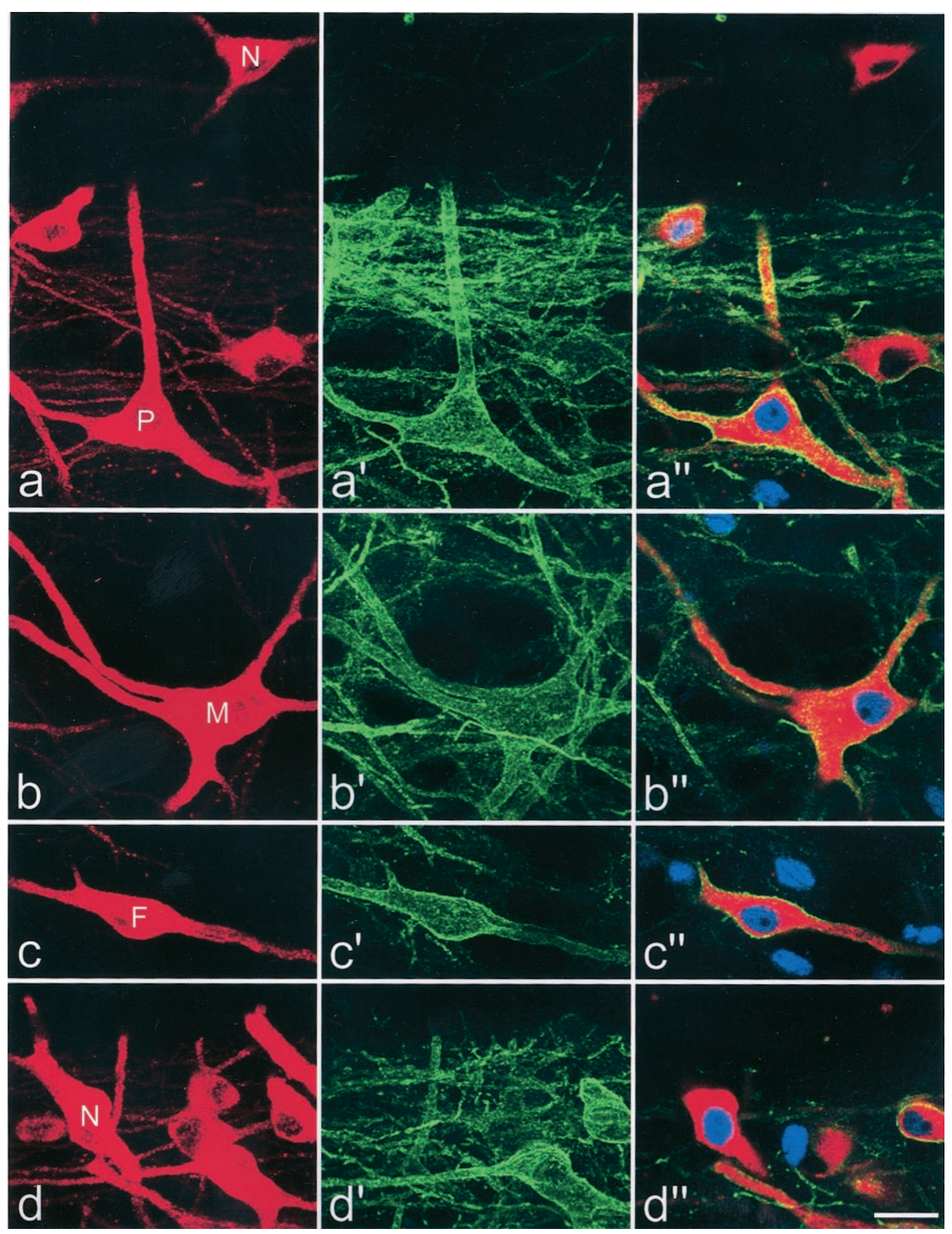

Figure 8. Expression of c-Fos in lamina I projection neurons. In each row, the left panel shows immunostaining for $\mathrm{CTb}($ red $)$ in a projected image from a confocal series, and the center panel shows the equivalent field scanned for NK1 receptor immunoreactivity (green). The right panel is a single optical section from the confocal series showing CTb (red), NK1 receptor ( green), and c-Fos (blue). a, A CTb-labeled pyramidal cell ( $P$ ) with the NK1 receptor has c-Fos in its nucleus, whereas another pyramidal neuron that lacks the receptor $(N)$ is not c-Fos-immunoreactive. $b, c$, Multipolar $(M)$ and fusiform $(F)$ cells with the NK1 receptor have nuclear c-fos. $d$, This field contains several neurons, including one that is not NK1 receptor-immunoreactive $(N)$ but has a nucleus that is c-Fos-immunoreactive. Projections in $a-d$ are from seven, seven, five, and seven optical sections, respectively, at $2 \mu \mathrm{m}$ $z$-separation. Scale bar, $20 \mu \mathrm{m}$. 
ent morphological classes, throughout this study we selected NK1 receptor-immunoreactive projection neurons that could reliably be assigned to one of the three classes, and we excluded cells that were atypical or transitional. Because many cells could not be classified, we were unable to determine the proportion of neurons in each morphological class that were retrogradely labeled in these experiments. However, during the analysis of the c-Fos experiments, we found that typical pyramidal, fusiform, and multipolar neurons occurred with approximately equal frequency among the NK1 receptor-immunoreactive population.

Lamina I projection neurons with the NK1 receptor received significantly more contacts from substance P-containing primary afferents than did projection neurons that lacked the receptor. The figures for the latter group included all substance P-containing axons, because CGRP was not detected in these sections (see above), and therefore the density of contacts from substance $\mathrm{P}$ primary afferents would presumably have been slightly lower than the figures obtained. Because of the high density of substance P-containing axons in lamina I, it is likely that many appositions involving these axons occurred by chance. However, the presence of numerous contacts from substance P primary afferents on stretches of dendritic or somatic membrane (Figs. 5, 6c), which was seen on all of the NK1 receptorimmunoreactive neurons, suggests a targeted innervation of these cells. Electron microscopy of a sample of contacts on six NK1 receptor-immunoreactive projection neurons confirmed that the great majority of substance $\mathrm{P}$ primary afferents that contacted these cells formed synapses. Because substance P is likely to act through volume transmission, the presence of asymmetrical synapses at these contacts suggests that glutamate acts as a transmitter in this situation (De Biasi and Rustioni, 1988; Broman et al., 1993). McLeod et al. (1998) reported that dendrites with the NK1 receptor in lamina I have a higher frequency of synapses from substance P-immunoreactive axons than dendrites that lack the receptor, and our findings are consistent with this observation.

We have previously shown that NK1 receptor-immunoreactive projection neurons with cell bodies in laminas III or IV and dendrites that enter the superficial laminas also receive dense synaptic innervation from substance $\mathrm{P}$ primary afferents (Naim et al., 1997; Todd et al., 2000). These cells had on average 18.8 contacts $/ 100 \mu \mathrm{m}$ from substance P-containing axons onto dendrites within laminas I and II (Naim et al., 1997), and this is similar to the mean contact density for substance P-CGRPimmunoreactive varicosities on dendrites of the NK1 receptorimmunoreactive lamina I neurons in the present study (16.2/100 $\mu \mathrm{m})$. These results indicate that both groups of projection neurons are major synaptic targets for substance P-containing primary afferents in the superficial dorsal horn.

c-Fos expression by lamina I projection neurons in response to formalin injection was more closely related to presence of the NK1 receptor than to morphology (Table 1). Basal levels of c-Fos are very low in the dorsal horn, and because innocuous stimulation does not result in expression by neurons in lamina I (Hunt et al., 1987), the presence of c-Fos in lamina I neurons in this study can be taken as evidence that they were activated by chemical and/or mechanical nociceptors. Han et al. (1998) reported that all pyramidal cells in lamina I of the cat spinal cord were coolingspecific and did not respond to noxious stimulation, and in agreement with this Yu et al. (1999) observed that only $25 \%$ of pyramidal spinothalamic neurons in the monkey were NK1 receptor-immunoreactive. Surprisingly, we found that $>80 \%$ of projection neurons with typical pyramidal morphology were NK1 receptor-immunoreactive and that $\sim 80 \%$ of these cells expressed c-Fos. It therefore seems that in the rat, unlike the situation reported in cat, many pyramidal neurons in lamina I are activated by nociceptors. The lamina I component of the spinothalamic tract appears to be relatively small in the rat compared with that in the cat and monkey (Marshall et al., 1996; Zhang et al., 1996; Zhang and Craig, 1997), and at least some of the neurons examined in the study of Han et al. (1998) belonged to this tract. If the relationship between morphology and receptive field properties for spinothalamic tract neurons is different from that for cells belonging to other tracts, this may account for the discrepancy between our results and those of Han et al. (1998) and Yu et al. (1999).

Although c-Fos expression was more common in projection neurons with the NK1 receptor, between 25 and $45 \%$ of those without the receptor also expressed c-Fos, and therefore a significant proportion of these cells were excited by noxious stimulation. Mantyh et al. (1997) reported that intrathecal infusion of substance $\mathrm{P}$-saporin in rats caused destruction of $85 \%$ of $\mathrm{NK} 1$ receptor-immunoreactive neurons in lamina I and apparent damage to the remainder. Although these animals showed dramatic reduction of hyperalgesia, their responses to acute noxious stimuli were normal. Lamina I projection neurons that lack the NK1 receptor but are activated by nociceptors may therefore have contributed to the responses to acute stimuli in the substance $\mathrm{P}$-saporin-treated animals.

Although c-Fos is a useful marker for cells that have been activated by a stimulus, lack of c-Fos expression is more difficult to interpret. The neurons that were not c-Fos-immunoreactive after formalin injection may have received input from nociceptors that were not activated by the stimulus or may have been excited without expressing c-Fos. Bester et al. (2000) found that all of their sample of rat spinoparabrachial lamina I neurons responded to noxious stimulation, however, there are known to be projection cells in this lamina in other species that respond only to innocuous cooling (Han et al., 1998). If cooling-specific projection neurons are present in the rat, they would presumably have been included among those that were not c-Fos-immunoreactive. Because all NK1 receptor-immunoreactive projection neurons in lamina I appear to be innervated by substance P-containing (nociceptive) primary afferents, it is likely that any coolingspecific neurons would be found among the cells that lack the receptor.

In conclusion, our results suggest that for lamina I projection neurons in the rat that are retrogradely labeled from the CVLM, presence or absence of the NK1 receptor provides a better indication of primary afferent input and the response to acute noxious stimulation than does somatodendritic morphology.

\section{REFERENCES}

Bester H, Chapman V, Besson J-M, Bernard J-F (2000) Physiological properties of the lamina I spinoparabrachial neurons in the rat. J Neurophysiol 83:2239-2259.

Bleazard L, Hill RG, Morris R (1994) The correlation between the distribution of $\mathrm{NK}_{1}$ receptor and the actions of tachykinin agonists in the dorsal horn of the rat indicates that substance $\mathrm{P}$ does not have a functional role on substantia gelatinosa (lamina II) neurons. J Neurosci 14:7655-7664.

Broman J, Anderson S, Ottersen OP (1993) Enrichment of glutamatelike immunoreactivity in primary afferent terminals throughout the spinal cord dorsal horn. Eur J Neurosci 5:1050-1061.

Brown JL, Liu H, Maggio JE, Vigna SR, Mantyh PW, Basbaum AI (1995) Morphological characterization of substance $P$ receptorimmunoreactive neurons in rat spinal cord and trigeminal nucleus caudalis. J Comp Neurol 356:327-344. 
Cheunsuang O, Morris R (2000) Spinal lamina I neurons that express neurokinin 1 receptors: morphological analysis. Neuroscience 97:335-345. Christensen BN, Perl ER (1970) Spinal neurons specifically excited by noxious or thermal stimuli: marginal zone of the dorsal horn. J Neurophysiol 33:293-307.

Craig AD (1995) Distribution of brainstem projections from spinal lamina I neurons in the cat and monkey. J Comp Neurol 361:225-248.

De Biasi S, Rustioni A (1988) Glutamate and substance P coexist in primary afferent terminals in the superficial laminae of the spinal cord. Proc Natl Acad Sci USA 85:7820-7824.

Doyle C, Hunt SP (1999) Substance P receptor (neurokinin-1)expressing neurons in lamina $I$ of the spinal cord encode for the intensity of noxious stimulation: a c-fos study in the rat. Neuroscience 89:17-28.

Ferrington DG, Sorkin LS, Willis WD (1987) Responses of spinothalamic tract cells in the superficial dorsal horn of the primate lumbar spinal cord. J Physiol (Lond) 388:681-703.

Giesler GJ, Menetrey D, Basbaum AI (1979) Differential origins of spinothalamic tract projections to medial and lateral thalamus in the rat. J Comp Neurol 184:107-125.

Gobel S (1978) Golgi studies of the neurons in layer I of the dorsal horn of the medulla (trigeminal nucleus caudalis). J Comp Neurol 180:375-394.

Han Z-S, Zhang E-T, Craig AD (1998) Nociceptive and thermoreceptive lamina I neurons are anatomically distinct. Nat Neurosci $1: 218-225$.

Hökfelt T, Kellerth JO, Nilsson G, Pernow B (1975) Substance P: localization in the central nervous system and in some primary sensory neurons. Science 190:889-890.

Hunt SP, Pini A, Evan G (1987) Induction of c-fos-like protein in spinal cord neurons following sensory stimulation. Nature 328:632-634.

Ju G, Hökfelt T, Brodin E, Fahrenkrug J, Fischer JA, Frey P, Elde RP, Brown JC (1987) Primary sensory neurons of the rat showing calcitonin gene-related peptide immunoreactivity and their relation to substance P-, somatostatin-, galanin-, vasoactive intestinal polypeptideand cholecystokinin-immunoreactive ganglion cells. Cell Tissue Res 247:417-431.

Lawson SN, Crepps BA, Perl ER (1997) Relationship of substance P to afferent characteristics of dorsal root ganglion neurones in guinea-pig. J Physiol (Lond) 505:177-191.

Light AR, Trevino DL, Perl ER (1979) Morphological features of functionally defined neurons in the marginal zone and substantia gelatinosa of the spinal dorsal horn. J Comp Neurol 186:151-172.

Lima D, Mendes-Ribeiro JA, Coimbra A (1991) The spino-lateroreticular system of the rat: projections from the superficial dorsal horn and structural characterization of marginal neurons involved. Neuroscience 45:137-152.

Littlewood NK, Todd AJ, Spike RC, Watt C, Shehab SAS (1995) The types of neuron in spinal dorsal horn which possess neurokinin-1 receptors. Neuroscience 66:597-608.

Llewellyn-Smith IJ, Minson JB (1992) Complete penetration of antibodies into Vibratome sections after glutaraldehyde fixation and ethanol treatment: Light and electron microscopy for neuropeptides. J Histochem Cytochem 40:1741-1749.

Mantyh PW, DeMaster E, Malhotra A, Ghilardi JR, Rogers SD, Mantyh CR, Liu H, Basbaum AI, Vigna SR, Maggio JE, Simone DA (1995) Receptor endocytosis and dendrite reshaping in spinal neurons after somatosensory stimulation. Science 268:1629-1632.
Mantyh PW, Rogers SD, Honore P, Allen BJ, Ghilardi JR, Li J, Daughters RS, Lappi DA, Wiley RG, Simone DA (1997) Ablation of lamina I spinal neurons expressing the substance $\mathrm{P}$ receptor profoundly inhibits hyperalgesia. Science 278:275-279.

Marshall GE, Shehab SAS, Spike RC, Todd AJ (1996) Neurokinin-1 receptors on lumbar spinothalamic neurons in the rat. Neuroscience 72:255-263.

McLeod AL, Krause JE, Cuello AC, Ribeiro-da-Silva A (1998) Preferential synaptic relationships between substance $\mathrm{P}$-immunoreactive boutons and neurokinin 1 receptor sites in the rat spinal cord. Proc Natl Acad Sci USA 95:15775-15780.

Menétrey D, Chaouch A, Besson JM (1982) The origins of the spinomesencephalic tract in the rat: an anatomical study using the retrograde transport of horseradish peroxidase. J Comp Neurol 206:193-207.

Naim M, Spike RC, Watt C, Shehab SAS, Todd AJ (1997) Cells in laminae III and IV of the rat spinal cord which possess the neurokinin-1 receptor and have dorsally-directed dendrites receive a major synaptic input from tachykinin-containing primary afferents. J Neurosci 17:5536-5548.

Nakaya Y, Kaneko T, Shigemoto R, Nakanishi S, Mizuno N (1994) Immunohistochemical localization of substance $\mathrm{P}$ receptor in the central nervous system of the adult rat. J Comp Neurol 347:249-274.

Paxinos G, Watson C (1997) The rat brain in stereotaxic coordinates, Ed 3. San Diego: Academic.

Polgár E, Shehab SAS, Watt C, Todd AJ (1999) GABAergic neurons that contain neuropeptide Y selectively target cells with the neurokinin 1 receptor in laminae III and IV of the rat spinal cord. J Neurosci 19:2637-2646.

Todd AJ, Spike RC (1993) The localization of classical transmitters and neuropeptides within neurons in laminae I-III of the mammalian spinal dorsal horn. Prog Neurobiol 41:609-646.

Todd AJ, Spike RC, Polgár E (1998) A quantitative study of neurons

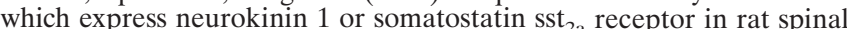
dorsal horn. Neuroscience 85:459-473.

Todd AJ, McGill MM, Shehab SAS (2000) Neurokinin 1 receptor expression by neurons in laminae I, III and IV of the rat spinal dorsal horn that project to the brainstem. Eur J Neurosci 12:689-700.

Trevino DL, Carstens E (1975) Confirmation of the location of spinothalamic neurons in the cat and monkey by the retrograde transport of horseradish peroxidase. Brain Res 98:177-182.

Vigna SR, Bowden JJ, McDonald DM, Fisher J, Okamoto A, McVey DC, Payan DG, Bunnett NW (1994) Characterization of antibodies to the rat substance $\mathrm{P}(\mathrm{NK}-1)$ receptor and to a chimeric substance $\mathrm{P}$ receptor expressed in mammalian cells. J Neurosci 14:834-845.

Villanueva L, Bernard J-F (1999) The multiplicity of ascending pain pathways. In: Handbook of behavioral state control: cellular and molecular mechanisms (Lydic R, Baghdoyan HA, eds), pp 569-585. Boca Raton, FL: CRC.

Yu XH, Zhang ET, Craig AD, Shigemoto R, Ribeiro-da-Silva A, De Koninck Y (1999) NK-1 receptor immunoreactivity in distinct morphological types of lamina I neurons of the primate spinal cord. J Neurosci 19:3545-3555.

Zhang ET, Craig AD (1997) Morphology and distribution of spinothalamic lamina I neurons in the monkey. J Neurosci 17:3274-3284.

Zhang ET, Han Z-S, Craig AD (1996) Morphological classes of spinothalamic lamina I neurons in the cat. J Comp Neurol 367:537-549. 